\title{
Toward understanding Malaysian fishermen's decision making on the use of fishing technology: a mental model approach
}

\begin{abstract}
The vast majority of Malaysia's fishermen are located in rural areas, specifically in the Western and Eastern coastal regions of Peninsular Malaysia and the Sabah and Sarawak central zones. In these areas, the fishing industry is relied upon as a major economic contributor to the region's residents. Despite the widespread application of various modern technologies into the fishing industry (i.e., GPS, sonar, echo sounder, remote sensing), and the Malaysian government's efforts to encourage their adoption, many small-scale fishermen in the country's rural areas continue to rely on traditional fishing methods. This refusal to embrace new technologies has resulted in significant losses in fish yields and needed income, and has raised many questions regarding the inputs to decision making of the fishermen. Drawing on multiple literatures, in this article we argue for the use of a mental model approach to gain an in-depth understanding of rural Malaysian fishermen's choices of technology adoption according to four main constructs-prior experience, knowledge, expertise and beliefs or values. To provide needed inputs to agricultural specialists and related policy makers for the development of relevant plans of action, this article aims to provide a way forward for others to understand dispositional barriers to technology adoption among fishermen who use traditional methods in non-Western contexts.
\end{abstract}

Keyword: Fishing industry; Fishing technologies; Mental models; Socioeconomic status 